\title{
Intra-articular rheumatoid nodules and triggering of the knee joint
}

\author{
Z Tak-Diamant, F J J Hooning van Duyvenbode, F Eulderink, M Janssen
}

\begin{abstract}
Rheumatoid nodules are a common extraarticular manifestation in rheumatoid arthritis. Intra-articular localisation of these nodules is rare and may produce clinical symptoms. Seven patients with walking problems due to an intra-articular rheumatoid nodule, which became entrapped on the ridge of the tibial plateau of the knee joint resulting in a phenomenon referred to as trigger knee, are described. After excision of the nodules all symptoms completely disappeared.
\end{abstract}

Rheumatoid nodules are characteristic extraarticular manifestations of rheumatoid arthritis. They are mainly found in the presence of rheumatoid factor ${ }^{1}$ and may be indicative of more severe disease. ${ }^{2}$ These nodules occur in $20-35 \%$ of patients with rheumatoid arthritis and they are commonly found subcutaneously over pressure points-for example, at the elbows, the buttocks, and the scalp. ${ }^{1}$ They can also develop in several internal organs, such as the lungs, kidneys, and heart. ${ }^{3}{ }^{4}$ Intra-articular rheumatoid nodules, however, are rare. ${ }^{5-9}$ In this retrospective study we considered seven patients with walking problems associated with intra-articular rheumatoid nodules of the knee joint.

Patients and methods

From 1972 to 1989 six patients who visited our outpatient rheumatology clinic had seropositive rheumatoid arthritis and symptoms typical of intra-articular rheumatoid nodules of the knee joint. We also performed a computer search for patients who had had an operation for triggering of the knee joint caused by rheumatoid nodules and another patient was identified. We retrospectively studied the clinical features associated with the presence of intra-articular rheumatoid nodules in these seven patients.

Clinical data were collected from medical files. Preoperative radiographs of the affected knees were compared with those of the unaffected knees using the score system described by Larsen $e t$ al. ${ }^{10}$ Operative data and postoperative course were reviewed.

The diagnosis of rheumatoid nodule was based on history and physical examination and was confirmed by histological examination of the excised lumps. Central fibrinoid necrosis surrounded by palisading histiocytic cells was considered diagnostic of rheumatoid nodules (figs 1 and 2).

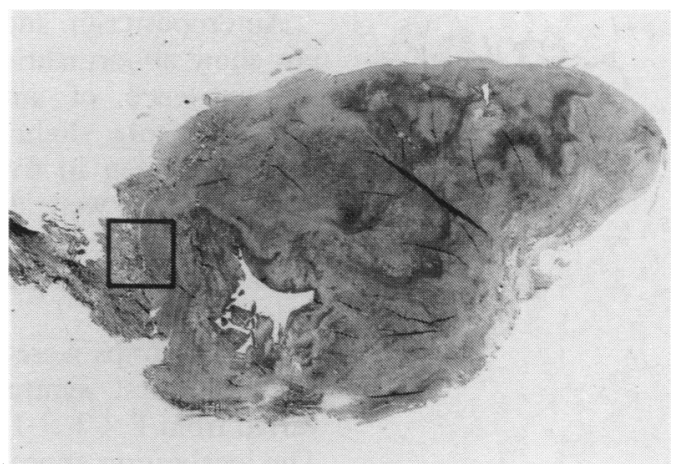

Figure 1 Rheumatoid nodule showing central fibrinoid necrosis. The boxed area is shown in detail in fig 2.

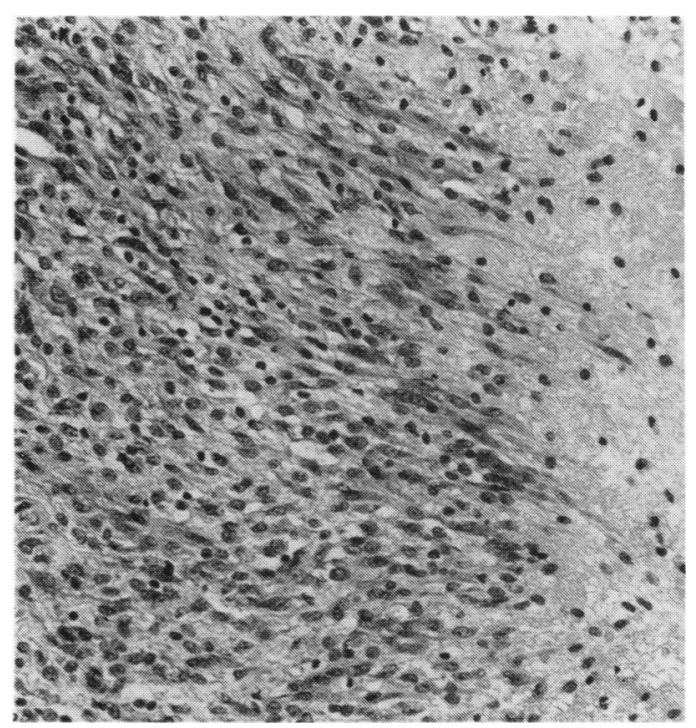

Figure 2 Detail of fig 1 showing typical palisades of histiocytic cells surrounding the necrotic centre.

\section{Results}

Six women and one man were identified with symptoms during walking caused by intraarticular rheumatoid nodules. All patients had seropositive rheumatoid arthritis. The mean disease duration was 11.9 years (range 3-33 years, $S D=10 \cdot 7)$. The mean age of the patients was 53 years (range 39-69 years).

All patients had a history of recurrent pain accompanied by clicking, locking, and giving way of the affected knee joint. In three patients this triggering of the knee joint occasionally caused stumbling and falling. It was noted in one patient that in the presence of a gross joint effusion the triggering and pain disappeared. It recurred soon after removal of the synovial fluid, or after the administration of an intraarticular injection of corticosteroids. 
On physical examination a moderate synovitis with slight effusion was found in four patients and a firm lump was palpable in all seven. The lump appeared to be attached to the capsule. In six patients the lump was situated on the lateral side and in one patient on the medial side of the patella. On flexing the knee, the lump slipped over the underlying tibial plateau and hid behind the patella. Sometimes it was caught on the tibial plateau and caused triggering of the knee joint. This could be perceived as a palpable 'click'.

Anteroposterior and lateral radiographs did not show abnormalities that could account for the presence of intra-articular rheumatoid nodules. Only slight narrowing of the joint space was seen in five patients (Larsen score 0-1). Erosions were absent. In two patients the radiographs were normal. Affected and unaffected knees could not be distinguished radiologically.

All the lumps were excised within two years after the first symptoms. Their dimensions varied from $1 \times 1 \times 1 \mathrm{~cm}$ to $3 \times 2.5 \times 1.5 \mathrm{~cm}$. The localisation appeared to be intracapsularthat is, within the fibrous capsule of the knee joint.

In six of the seven patients the diagnosis of rheumatoid nodule was confirmed by histological findings. In one patient insufficient material was obtained for histological examination. The synovium showed a mild inflammatory reaction in all patients.

The postoperative course was uneventful in all but one patient. In this patient haemarthrosis developed within two weeks during anticoagulant prophylaxis. In all patients triggering of the knee disappeared after removal of the rheumatoid nodules. Two patients had a symptomatic recurrence of the rheumatoid nodule within one and two years. Two to seven years after excision the others were still asymptomatic.

\section{Discussion}

Walking problems are a common clinical symptom in patients with rheumatoid arthritis. Usually they are due to arthritis, instability of the lower limb joints, or loss of muscle strength. Rare causes of walking problems in rheumatoid arthritis include normal pressure hydrocephalus $^{11}$ and myelopathy. ${ }^{12}$

We report here intra-articular rheumatoid nodules of the knee joint as another cause of walking problems in patients with seropositive rheumatoid arthritis. Entrapment of an intraarticular rheumatoid nodule on the ridge of the tibial plateau has an easily recognisable clinical pattern consisting of clicking, locking, and giving way of the knee joint. This clinical pattern is comparable with trigger finger or trigger wrist. ${ }^{8}$ Thus 'trigger knee' seems to be the most suitable name for this phenomenon. Chamberlain ${ }^{5}$ reported another clinical feature of intra-articular rheumatoid nodules, namely the lack of full extension of the knee, resulting in walking problems. In three of our patients triggering of the knee joint resulted in stumbling and falling. To our knowledge, such severe walking problems have not yet been reported in association with intra-articular rheumatoid nodules.

The differential diagnosis of triggering of the knee joint also includes intra-articular loose bodies, menisceal tears and cysts, ganglions, and patellar osteophytes.

In our patients the presumed diagnosis of intra-articular rheumatoid nodules of the knee joint was easily made solely by history and physical examination. Ultrasonography is possibly useful in distinguishing intra-articular rheumatoid nodules in several joints. ${ }^{13-16}$ As a result of the localisation of the rheumatoid nodules within the fibrosis capsule, we conclude that arthroscopy will be superfluous in most patients with intra-articular rheumatoid nodules of the knee joint.

In our series of patients anteroposterior and lateral radiographs of the affected knees showed surprisingly little damage and had a similar Larsen score to those of the unaffected knees, as shown by other workers. ${ }^{5-7}$

In conclusion, intra-articular rheumatoid nodules can cause serious walking problems in patients with seropositive rheumatoid arthritis due to triggering of the knee joint, as a result of entrapment of the nodule on the ridge of the tibial plateau. This phenomenon is probably rare: only seven patients with trigger knee caused by intra-articular rheumatoid nodules were identified during 17 years in our rheumatology outpatient clinic. As most of the intraarticular rheumatoid nodules will probably remain symptomless, it is difficult to predict how often they really occur. In accordance with the other workers, ${ }^{5-7}$ most of the nodules were located on the lateral side of the patella $(86 \%$ of patients) and only one (14\%) medially. The diagnosis can easily be made on the basis of the typical clinical manifestations and confirmed by histological examination. No additional investigations are required. Complete relief of the symptoms can be obtained by excision of the nodule.

The authors thank Dr J D Macfarlane for revising the English text.

1 Harris E D. The clinical features of rheumatoid arthritis. In: Kelley W N, Harris E D, Ruddy S, Sledge C B, eds. Textbook of rheumatology. 3rd ed. Philadelphia: Saunders, 1989: $965-6$.

2 van der Heyde D M F M, van Riel P L C M, van Rijswijk M H, van der Putte L B A. Influence of prognostic features $M H$, van der Putte L B A. Influence of prognostic features
on the outcome in rheumatoid arthritis: a review of the on the outcome in rheumatoid arthritis: a review
literature. Semin Arthritis Rheum 1988; 17: 284-92.

3 Schumacher J R. Primer on the rheumatic diseases. 9th ed. Atlanta, GA: Arthritis Foundation, 1988: $90-2$.

4 Krane S M, Simon L S. Rheumatoid arthritis: clinical features and pathogenetic mechanisms. Med Clin North Am 1986; 70: 263-84

5 Chamberlain $M A$. Intra-articular rheumatoid nodules of the knee. F Bone foint Surg [Br] 1971; 53: 507-9.

6 Kampner S L, Kuzell W. Intra-articular rheumatoid nodule of the knee joint. Clin Orthop 1976; 114: 243-6.

7 Huang T L, Fossier C, Ray R D, Ghosh L. Intra-articular rheumatoid nodule of the knee joint associated with recurrent subluxation of the patella. $\mathcal{F}$ Bone foint Surg [Am] 1979; 61: 438-40.

8 Carvell J E, Mowat A G, Fuller D J. Trigger wrist phenomenon in rheumatoid arthritis. Hand 1983; 15: $77-81$.

9 Ishikawa $\mathrm{H}$, Ueba $\mathrm{Y}$, Hirohata $\mathrm{K}$. An intra-articular rheuma toid nodule of the hip. $\mathcal{F}$ Bone foint Surg [Am] 1988; 70: 775-7. 
10 Larsen A, Dale K, Eek M. Radiographic evaluation of rheumatoid arthritis and related conditions by standard reference films. Acta Radiol [Diagn] 1977; 18: 481-91.

11 Rasker J J, Jansen E N H, Haan J, Oostrom J. Normalpressure hydrocephalus in rheumatic patients. $N$ Engl $\mathcal{J}$ Med 1985; 312: 1239-41.

12 van der Horst-Bruinsma I E, Markusse H M, Macfarlane J D, Vielvoye C J. Rheumatoid discitis with cord compression at the thoracic level. Br $\mathcal{F}$ Rheumatol 1990; 29: 65-8.

13 Sattler H, Schmidt K L. Zum Stellenwert der Arthrosono- graphie in der rheumatologischen Diagnostik: Untersuchungstechnik, Befunde und ihre Interpretation. Z Rheumatol 1986; 45: 1-6.

14 De Flaviis L, Scaglione P, Nessi R, Ventura R, Calori G. Ultrasonography of the hand in rheumatoid arthritis. Acto Radiol 1988; 29. 457-60.

15 Koski J M. Axillar ultrasound of the glenohumeral joint. J Rheumatol 1989; 16: 664-7.

16 Goldenstein C, McCauley R, Troy M, Schaller J G, Szer I S. Ultrasonography in the evaluation of wrist swelling in children. $\mathcal{f}$ Rheumatol 1989; 16: 1079-87. 


\section{MATTERS ARISING}

\section{Treatment of resistant giant cell arteritis with etanercept}

Tan et al recently described a case of "resistant giant cell arteritis" successfully treated with etanercept. ${ }^{1}$ Their patient, who had classical symptoms of polymyalgia rheumatica (PMR), developed headaches while receiving low dose steroids. Biopsy of a temporal artery showed no arteritis. Because giant cell arteritis (GCA) was suspected on clinical grounds, high dose steroids were instituted. Six months later, despite continued steroid treatment, a transient ischaemic attack (TIA) involving right arm weakness occurred, which was ascribed to "arteritis (sic)". An insufficiency fracture ensued. As the erythrocyte sedimentation rate and $\mathrm{C}$ reactive protein were persistently raised, a diagnosis of GCA resistant to treatment was made, and etanercept was given. The acute phase reactants normalised, and the symptoms referable to PMR resolved completely.

I am not persuaded that the patient in question had GCA.

Firstly, the temporal artery biopsy was negative. Definitive criteria for the entity of so-called biopsy negative GCA are lacking, and, in my opinion, this concept remains a problematic one. Negative temporal artery (TA) biopsies do occur in certain subsets of GCA-for example, upwards of $50 \%$ of patients with so-called large artery involvement have such negative biopsies ${ }^{2}$ - but the extent to which TA biopsies are negative in bona fide cases of cranial arteritis in GCA is unclear. Two recent papers have suggested that in fact a unilateral TA biopsy negative for arteritis markedly reduces the probability of the diagnosis of GCA, because the yield of a positive contralateral biopsy is no more than $1-3 \%{ }^{34}$

The issue of what constitutes a flare in GCA (and PMR) is also problematic. It has been my experience over the years that many cases of alleged flares of both conditions involve little more than asymptomatic rises in the acute phase reactants, and that the pursuit of such rises with increased doses of steroids not uncommonly results in sundry untoward complications-notably, steroid induced osteoporosis and associated fractures.

The patient under discussion is a case in point. The acute phase reactants were raised coincident with the occurrence of a TIA, but it is unlikely that this latter episode was caused by GCA. Though GCA is occasionally complicated by stroke, such an event nearly always involves the territory of the vertebral-basilar circulation, and rarely occurs in the distribution of the internal carotid artery. The explanation for this fact may result from the specific exclusion of the intracranial arteries from involvement by GCA, possibly because these arteries lack an internal elastic lamina, which plays a pivotal part in the pathogenesis of GCA. The internal elastic lamina is said to be maintained for a few millimetres after the vertebral arteries pierce the dura, thus accounting for the strokes referable to the vertebral-basilar circulation. ${ }^{5}$ The patient described by Tan et al had left arm weakness, almost surely attributable to ischaemia of the middle cerebral artery, thus effectively ruling out GCA as the cause for the TIA.

I therefore submit that this patient did not have "resistant giant cell arteritis"; rather, he represents a case of the successful treatment by tumour necrosis factor $\alpha$ $(\mathrm{TNF} \alpha)$ blockade of symptoms and signs referable to PMR.

One final caveat: although further study may show that TNF $\alpha$ blockade does successfully reduce the levels of cytokines that drive the acute phase response in GCA, thus ameliorating constitutional symptoms and signs, this treatment may not mitigate the disease's most feared consequence-namely, ischaemia leading to visual loss. As demonstrated by elegant work over the past decade by Weyand and Goronzy, ${ }^{6}$ ischaemia in GCA results from an array of other cytokines with pathogenic potential-for example, platelet derived growth factor and vascular endothelial growth factor, which would be unaffected by TNF $\alpha$ blockade.

W P Docken

Brigham and Women's Hospital, Boston, MA 02115 , USA

Correspondence to: Dr W P Docken, 850 Boylston St Chestnut Hill, MA 02467, USA; wdocken@partners.org

\section{References}

1 Tan AL, Holdsworth J, Pease C, Emery P, McGonagle D. Successful treatment of resistant giant cell arteritis with etanercept. Ann Rheum Dis 2003.62:373-4.

2 Brack A, Martinez-Taboada V, Stanson A, Goronzy JJ, Weyand CM. Disease pattern in cranial and large-vessel giant cell arteritis. Arthritis Rheum 1999:42:311-17.

3 Hall JK, Volpe NJ, Galeta SL, Grant TL, Syed NA, Balcer U. The role of unilateral temporal artery biopsy. Ophthalmology 2003; 110:543-8.

4 Boyev LR, Miller NR, Green WR. Efficacy of unilateral versus bilateral temporal artery biopsies for the diagnosis of giant cell arteritis. Am J Ophthalmol 1999:128:211-15.

5 Wilkinson IMS, Russell RWR. Arteries of the head and neck in giant cell arteritis: a pathologic study to show the pattern of arterial involvement. Arch Neurol 1972;27:378-91.

6 Weyand CM, Goronzy JJ. Medium- and large-vessel vasculitis. N Engl J Med 2003;349:160-9.

\section{Authors' reply}

We thank Dr Dockens for his comments on the difficulty in the diagnosis, treatment, and classification of polymyalgia rheumatica (PMR) and giant cell arteritis (GCA). However, the sole purpose of our case report was to show how etanercept might have a role in the treatment of resistant disease of the PMR/GCA spectrum. From a clinical standpoint we are happy to label our patient as having GCA (in addition to PMR) based on his headaches, reported visual abnormalities, temporal tenderness, and resistance to $15 \mathrm{mg}$ of prednisolone a day. We know that the disease was resistant because his symptoms and laboratory abnormalities persisted despite continued use of relatively high dose steroids, and there was clinical deterioration mirrored by an increase of the acute phase response.

Of course it is entirely possible that his transient ischaemic attack was related to atheroma, even in the face of very active GCA, but a rare arteritic related event could not be excluded in the clinical circumstances. The adverse effect of high dose steroids on blood pressure and lipid profiles and their association with atheromatous related disease was an additional concern about their continued use. We agree that it would be folly to treat patients on the basis of a raised erythrocyte sedimentation rate (ESR) alone but an extremely high ESR, as in this case, invariably signifies disease flare. Activation of the inflammatory cascade has a pivotal role in the pathogenesis of GCA so it seems logical that anti-tumour necrosis factor treatment could abrogate this regardless of the other cytokine mediators of disease.

Fifteen months after the original case report the clinical diagnosis remains the same and the patient continues to experience flares in disease with tapering of the steroid dose below $5 \mathrm{mg} /$ day.

\section{Department of Rheumatology, University of Leeds, UK \\ Correspondence to: $\operatorname{Dr}$ D G McGonagle; d.g.mcgonagle@leeds.ac.uk}

\section{Fenofibrate and losartan}

The leader by Professor Bardin ${ }^{1}$ makes an excellent point. We could benefit from the hypouricaemic action of drugs that are not licensed for this use (for example, losartan and fenofibrate).

Other drugs in common use may also have a uricosuric effect. For example, atorvastatin can reduce serum uric acid concentrations in patients with peripheral arterial disease or hyperlipidaemia. ${ }^{2-4}$ However, the mechanisms involved are not clear cut; we speculate that atorvastatin can increase renal blood flow and decrease serum creatinine levels. ${ }^{2-4}$ Thus, the Medical Research Council/British Heart Foundation Heart Protection Study (HPS) showed that simvastatin decreased the deterioration of the glomerular filtration rate (GFR) over a period of 4.6 years in high risk patients with $(\mathrm{n}=5963)$ or without $(\mathrm{n}=14573)$ diabetes. ${ }^{5}$ This effect on GFR would almost certainly influence urate excretion. These statin mediated effects are relevant because, as Professor Bardin ${ }^{1}$ points out, patients with hyperuricaemia may also be dyslipidaemic.

Closer to the interests of rheumatologists are the non-steroidal anti-inflammatory drugs (NSAIDs). Some NSAIDs may exert a favourable effect on urate excretion. For example, diflunisal has been reported to have a uricosuric effect, although the inhibition of xanthine oxidase activity has also been proposed. ${ }^{67}$ Azapropazone (not used as a first line option) has been shown to lower serum urate levels. ${ }^{78}$ Indometacin may have uricosuric properties. ${ }^{7}$ Tiaprofenic acid 
is another NSAID with hypouricaemic effect. ${ }^{9}$

Aspirin has a bimodal effect on the renal handling of uric acid. High doses ( $>3 \mathrm{~g}$ /day) are uricosuric, while lower doses ( $1-2$ g/day) cause urate retention. ${ }^{10}$ At the lowest dose ( $75 \mathrm{mg} /$ day) aspirin caused a 15\% decrease in urate excretion with a slight but significant increase in serum urate levels. ${ }^{10}$

The clinical significance of these "additional" uricosuric effects remains to be established. There is also a need to assess the value of using combinations of these drugs (for example, losartan and fenofibrate together with an NSAID with beneficial effects on urate excretion)

The search for NSAIDs that do not exert renal toxicity may well be worthwhile because of their widespread use. Acute attacks of gout are usually treated with high doses of NSAIDs. It could be useful to have NSAIDs with uricosuric properties as well as the analgesic and anti-inflammatory effect.

S S Daskalopoulou, D P Mikhailidis Department of Clinical Biochemistry (Vascular Disease Prevention Clinics), Royal Free Hospital, Royal Free and University College Medical School, London, UK

V G Athyros, A A Papageorgiou Atherosclerosis Unit, 2nd Propedeutic Department of Internal Medicine, Aristotelian University, Hippocration Hospital, Thessaloniki, Greece

M Elisaf

Department of Internal Medicine, Medical School, University of loannina, Greece

Correspondence to: D P Mikhailidis, Department of Clinical Biochemistry (Vascular Disease Prevention Clinics), Royal Free Hospital, Royal Free and University College Medical School, Pond street, London NW3 2QG, UK mikhailidis@aol.com

\section{References}

1 Bardin T. Fenofibrate and losartan. Ann Rheum Dis 2003:62:497-8.

2 Elisaf $M$, Mikhailidis DP. Statins and renal function. Angiology 2002;53:493-502.

3 Youssef F, Gupta P, Seifalian AM, Myint F Mikhailidis DP, Hamilton G. The effect of shortterm treatment with simvastatin on renal function in patients with peripheral arterial disease. Angiology 2004;55:53-62.

4 Athyros VG, Papageorgiou AA, Elisaf M, Mikhailidis DP on behalf of the GREACE Study Collaborative Group. Statins and Renal Function in Patients with Diabetes Mellitus. Curr Med Res Opin 2003; 19:615-19.

5 Heart Protection Study Collaborative Group. MRC/BHF Heart Protection Study of cholesterollowering with simvastatin in 5963 people with diabetes: a randomised placebo-controlled trial. Lancet 2003:361:2005-16.

6 Ferraccioli G, Spisni A, Ambanelli U. Hypouricemic action of diflunisal in gouty patients: in vitro and in vivo studies. J Rheumato 1984; 11:330-2

7 Tiitinen S, Nissila M, Ruutsalo HM, Isomaki $\mathrm{H}$. Effect of nonsteroidal anti-inflammatory drugs on the renal excretion of uric acid. Clin Rheumatol 1983;2:233-6.

8 Higgens CS, Scott JT. The uricosuric action of azapropazone: dose-response and comparison with probenecid. Br J Clin Pharmacol 1984; 18:439-43.

9 Lyfar V, Fernandes L, Thornton E, Cook JG. A study of the hypouricaemic effect of tiaprofenic acid. Ann Clin Biochem 1988;25:595-600.

1988;25:595-600.
Caspi D, Lubart E, Graff E, Habot B, Yaron M, Segal R. The effect of mini-dose aspirin on renal function and uric acid handling in elderly patients. Arthritis Rheum 2000;43:103-8.
NOTIFICATION AND CORRECTION

Corrections printed in the journal also appear on the Annals website www.annrheumdis.com and are linked to the original publication

Intra-articular rheumatoid nodules and triggering of the knee joint (Tak-Diamant Z, Hooning van Duyvenbode FJ, Eulderink F, Janssen M. Ann Rheum Dis 1992;51:533-5.)

The name of the first author of this paper has changed from Tak-Diamant Z to Diamant $\mathrm{Z}$.

Does long term treatment with azathioprine predispose to malignancy and death in patients with systemic lupus erythematosus? (Nero P, Rahman A, Isenberg DA. Ann Rheum Dis 2004;63:325-6.) doi: 10.1136/ard.2002.005371 corr 1

We regret that the references for this letter were omitted. They are given below.

1. Hazleman B. Incidence of neoplasms in patients with rheumatoid arthritis exposed to different treatment regimens. Am J Med 1985;78(suppl 1A):39-43.

2. Moll JMH. Drug therapy (3): "specific" drugs. In: Management of rheumatic disorders. lst ed. London: Chapman and Hall: 1983:169-212.

3. Silman A, Petrie J, Hazleman B, Evans S. Lymphoproliferative cancer and other malignancy in patients with rheumatoid arthritis treated with azathioprine: a 20year follow up study. Ann Rheum Dis 1988;47:988-92.

4. Sutcliffe N, Smith C, Speight PM, Isenberg DA. Mucosa-associated lymphoid tissue lymphomas in two patients with rheumatoid arthritis on second-line agents, and secondary Sjögren syndrome. Rheumatology (Oxford) 2000;39:185-8.

\section{NOTICE}

\section{8th EULAR Postgraduate Course in Rheumatology}

28 November-3 December 2004; Prague, Czech Republic

The course will cover clinical aspects of rheumatic disease concentrating on outcome, assessment, and evidence based management and will include the scientific basis of rheumatology. The course is aimed at junior rheumatologists at the end of their training but is open to all rheumatologists.

The registration fee of $€ 600$ will include tuition, accommodation for seven nights and all meals.

The electronic registration system will open on 1 April 2004 on the EULAR website Www.eular.org

EULAR will consider granting bursaries to young rheumatologists from countries where there is a real educational need. More information will be available on the EULAR website from 1 April 2004.
EULAR Secretariat, Witikonerstrasse 15, CH 8032 Zurich, Switzerland

Tel: + 41 1 3839690

Fax: + 4113839810 Email: secretariat@eular.org Website: www.eular.org

\section{FORTHCOMING EVENTS}

\section{International Congress on SLE and Related Conditions}

9-13 May 2004; New York, New York, USA Contact: The Oakley Group, 2014 Broadway, Suite 250, Nashville, Tennessee 37203, USA Tel: +1 6153222785

Fax: +1 6153222784

Email: Lupus2004@theoakleygroup.com Website: http://www.lupus2004.org

\section{IOF World Congress on Osteoporosis}

14-18 May 2004; Rio de Janeiro, Brazil

IOF awards are available for scientists:

IOF Claus Christiansen Research Fellowship: 45000

IOF Servier Young Investigator Fellowship: 40000

Contact: Congress Secretariat at info@ osteofound.org

Website: www.osteofound.org

\section{International Society for the Study of} the Lumbar Spine

31 May-5 June 2004; Porto, Portugal Contact: International Society for the Study of the Lumbar Spine, 2075 Bayview Avenue, Room MG 323, Toronto, Ontario, Canada M4N 3M5

Tel: 0014164804833

Fax: 0014164806055

Email: shirley.fitzgerald@sw.ca

\section{8th EULAR Sonography Course}

7-9 June 2004; Berlin, Germany

Organising Committee: Marina Backhaus, Wolfgang Schmidt

Contact: Congress Organisation: Gedel Congress Service

Tel: $+49-30-22488390$

Fax: +49-30-22488389

Email: gedel.cm@t-online.de

Website: www.eular.org

\section{First European Course:} Capillaroscopy and Rheumatic Diseases

10-12 September 2004; Genova, Italy Contact: Scientific Secretariat: Professor Maurizio Cutolo, Division of Rheumatology, DIMI, University of Genova, Italy

Email: mcutolo@unige.it

Organising Secretariat: Michela Civelli, EDRA spa, Viale Monza , 133 - 20125, Milan, Italy Tel: +3902 281 72300

Fax: +3902 28172399

Email: edracongressi@dsmedigroup.com

\section{Xlth International Conference on Behçet's Disease}

27-31 October 2004; Antalya, Turkey Contact: Congress Secreteriat, Figur Congress and Organization Services Ltd. STI, Ayazmaderesi Cad. Karadut Sok. No: 7 80888 Dikilitas, Istanbul, Turkey

Tel: +90 (0212) 2586020

Fax: +90 (0212) 2586078

Email: behcet2004@figur.net

Website: www.behcet2004.org 